\title{
México y lo apocalíptico en Poemas civiles de Gabriel Trujillo Muñoz
}

Publicada en 2013, la colección de versos Poemas civiles, del escritor mexicano Gabriel Trujillo Muñoz, explora la actualidad mexicana a través de poemas que emplean imágenes y un lenguaje apocalíptico para retratar la profunda crisis nacional que está sufriendo la inmensa mayoría de sus residentes. A lo largo del poemario, se emplean imágenes apocalípticas para hacer abundantemente específica la distinción entre el México que fue, el México que es y el México que podrá ser, si no fuera por la pobreza, la violencia y la corrupción del país.

Palabras clave: Trujillo Muñoz, Poemas civiles, apocalipticismo, México, violencia

Published in 2013, the collection Poemas civiles, by the Mexican writer Gabriel Trujillo Muñoz, explores the Mexican present through a series of poems that use apocalyptic images and language to represent the profound national crisis suffered by the vast majority of residents. Apocalyptic images are used throughout the poems in order to distinguish between the Mexico that was, the Mexico that is, and the Mexico that might be, were it not for the country's poverty, violence, and corruption.

Keywords: Trujillo Muñoz, Poemas civiles, apocalypticism, Mexico, violence

En su poema "Corrido norteño a la manera de los hermanos Grimm," el escritor mexicano Gabriel Trujillo Muñoz declara que "En la frontera / Las fábulas maravillosas / Son cosa diaria" (Poemas 45). Conocido principalmente como autor de novelas y cuentos que encajan dentro del género fantástico y de la ciencia ficción, los poemas de Trujillo Muñoz representan un acercamiento a la realidad mexicana a través de una crítica de la delincuencia, de la pérdida de fe en la infraestructura jurídica y de la expansión de la violencia en su país. De ahí radica la relación entre la ciencia ficción y la realidad vivida a pie de calle: de la posibilidad de buscar y encontrar la lógica dentro de la ilógica. Según Trujillo Muñoz, la ciencia ficción "es un género que estimula la imaginación, un espacio especulativo, un laboratorio conceptual donde se ponen a prueba lo mismo esperanzas 
públicas que miedos colectivos, extrapolaciones científicas que visiones románticas del universo" (Biografías del futuro 22). Los versos de Poemas civiles (2013), sin embargo, se alejan de la ciencia ficción y logran plasmar estas "esperanzas públicas" y "miedos colectivos" en imágenes que profundizan en la actualidad nacional. Más específicamente, "[h]is position as an inhabitant of the border region provides him with a unique perspective - a view from the margin - that informs and enriches his work" (Trujillo Muñoz y Lockhart 2OI). Para nuestras intenciones, veremos que las imágenes apocalípticas que aparecen en los versos de Poemas civiles sirven para subrayar la actual decadencia social y política de México. Primero matizaremos lo apocalíptico para seguidamente ofrecer un análisis que se centra en los fenómenos naturales y la representación de animales y fauna que aparecen en los poemas y que, a nuestro parecer, resaltan el declive mexicano.

Como ha escrito Lois Parkinson Zamora, "El resurgimiento de modos de pensamiento y de expresión apocalípticos es una reacción predecible a la perturbación social y la incertidumbre moral, lo que explica su vigencia en nuestro actual vocabulario popular" (23). La crítica ha comentado ampliamente las características de la más reciente generación de escritores mexicanos, particularmente aquellos que han escrito de y desde el norte de México y la zona fronteriza. En términos elementales, "La literatura del Norte" o "la nueva narrativa del Norte" es "la producción literaria en los estados fronterizos de Baja California, Sonora, Coahuila, Chihuahua, Nuevo León y Tamaulipas, también como en los estados norteños no limítrofes, Sinaloa y Zacatecas" (Palaversich, "La nueva narrativa" IO). Esa literatura, distinta a la que se produce en otras partes de México, tiene sus raíces en las diferencias históricas y culturales entre esta región y el resto del país, particularmente en su proximidad a los Estados Unidos. Para Eduardo Antonio Parra:

El norte de México no es simple geografía: hay en él un devenir muy distinto al que registra la historia del resto del país; una manera de pensar, de actuar, de sentir y de hablar derivadas de ese mismo devenir y de la lucha constante contra el medio y contra la cultura de los Estados Unidos, extraña y absorbente. Derivadas también del rechazo al poder central; de la convivencia con las constantes oleadas de migrantes de los estados del sur y del centro; y de una mitología religiosa que se manifiesta en la adoración a santones regionales como la Santa de Cabora (Chihuahua), Juan Soldado (Baja California), el Niño Fidencio (Nuevo León) y Malverde (el 'santo' de los narcotraficantes sinaloenses). ("Notas") 
Según Frauke Gewecke, por ejemplo, la distinción entre norteños y nonorteños es clara: 'Son considerados como autores/autoras 'norteños' aquellos que nacieron o radican en la región y que escriben desde la frontera, vivida por lo general como experiencia-límite" (II2). Los orígenes de estas diferencias, sin embargo, son heterogéneos: "En los últimos años la narrativa escrita por norteños ha destacado en nuestras letras, debido, según ciertos críticos y lectores, a su vitalidad, a la búsqueda de una renovación en el lenguaje, a sus referencias constantes a la tradición literaria mexicana, a su estrecha relación con la realidad actual y, sobre todo, a la variedad de propuestas temáticas" (Parra, "Norte"). Diana Palaversich resalta que algunas características de esta literatura norteña incluyen "el empleo del lenguaje oral, el uso del idioma inglés, la descripción de la vida en la línea, el clima, el paisaje, la violencia y el narcotráfico" ("La nueva narrativa" 9-ı)). Para la escritora sonorense Eve Gil, "Vivir en la frontera ha repercutido en mi escritura; en mis caóticos procesos mentales, en el pesimismo burlón de mi mirada, en la acaso inconsciente reincidencia de personajes desajustados, inadaptados, melancólicos, solitarios y preescrizofrénicos [sic]". Radicado en la Ciudad de México, el ensayista y crítico Rafael Lemus, sin embargo, critica la postura superficial de una literatura norteña que simplemente toca por encima la realidad regional: "[La literatura norteña e]s populista y se vende a las clases medias. Es del norte pero se edita, preferentemente, en la capital y se lee en las apáticas ciudades del centro. Desde allí se los mira distantemente, con cierto morbo, sin afán de comulgar en su iconografía. A ese público se dirigen los autores del norte y, por lo mismo, rara vez evitan el didacticismo". La observación de Lemus critica que la "literatura norteña" se haya convertido en un producto cuyo propósito general es doble: aleccionar y vender ejemplares. Evidentemente, la tensión entre la periferia norteña y la metrópolis se hace palpable en los textos producidos desde cada región, y la perspectiva de Lemus resalta esas visiones enfrentadas. Sin embargo, la llamada nueva literatura norteña va más allá de plasmar cierto exotismo regional: a partir de su propio contexto y de un lenguaje que reflexiona sobre la frontera, las obras exploran qué significa ser el parachoques entre la cultura omnívora de los Estados Unidos y las distintas manifestaciones de lo mexicano.

Nacido en Mexicali, Baja California, Gabriel Trujillo Muñoz (1958) es actualmente profesor de la Facultad de Ciencias Humanas en la Universidad Autónoma de Baja California (UABC) y socio fundador de la Asociación Mexicana de Ciencia Ficción y Fantasía. Ejerce de codirector de Pórtico, la revista del Centro de escritura y apreciación literaria de la UABC, coordinador de la colección editorial de la UABC, Maestros del arte 
bajacaliforniano y co-coordinador de la colección de libros New Borders/Nuevas fronteras (UABC-UCCS-IVC-Editorial Artificios). Ha publicado más de cuarenta obras de narrativa, poesía y crítica que entran ampliamente en diálogo con la realidad nacional, particularmente con el tema de la identidad mexicana fronteriza. Varias de sus novelas, tales como Laberinto (1995), Espantapájaros (1999) y Trenes perdidos en la niebla (2010), emplean la fantasía y la ciencia ficción para indagar en la vida del norte de México y reflejan una fluidez y multiplicidad de perspectivas que ofrecen una mirada al cuestionamiento actual de fronteras y jerarquías. Como ha comentado Palaversich, su literatura dialoga con la construcción de una cultura popular mexicana y, por ende, latinoamericana: "En su construcción del espacio fronterizo Trujillo Muñoz no distingue entre la cultura 'alta' y 'baja' sino que les otorga el mismo lugar en su capacidad de perfilar la identidad cultural norteña" ("Paisajes" 272). Al utilizar la ciencia ficción para ir más allá de lo meramente utópico o distópico y retratar sus posibles matices sociales, Trujillo Muñoz subraya su potencial para documentar la actualidad y para ser, "simple y sencillamente, el espejo real de la nación mexicana, la pantalla fulgurante donde todo lo imposible está por suceder" (Biografías 24). Con respecto a su obra, la mayoría de la crítica se centra en explorar las variedades de hibridez mexicana (Knickerbocker) y la identidad fronteriza (Villalobos, Rodríguez Lozano), con un énfasis en la capacidad de discursos aparentemente antagónicos de expresar la distinción del norte de México. En este aspecto, los estudios coinciden en que la "identidad cultural" de la región es inseparable de las relaciones económicas y sociales que se mantienen con los Estados Unidos y recalcan la vida dinámica de la frontera.

Como espacio de tensión, la frontera entre México y los Estados Unidos y la inestable división entre éstos ha servido durante siglos como crisol de culturas y ejemplo de cómo la emigración, la corrupción, la violencia y la pobreza sirven para profundizar en los orígenes y las consecuencias de futuras crisis sociales, políticas, económicas y demográficas. Para escritores mexicanos como Trujillo Muñoz estas crisis también son síntomas de un apocalipsis nacional que refleja una época sacudida, un tiempo entre tiempos: el final de un mundo y el comienzo de otro. El origen del término apocalipsis, sin embargo, dista mucho de las actuales connotaciones políticas o sociales. Para el teólogo alemán Klaus Koch, lo apocalíptico "is understood to mean a complex writings and ideas which were widespread about the turn of the era in Palestine, in the Israelite diaspora and in early Christian circles; but which can also appear in similar form in other religious situations and mental climates" (I3). Frederick A. Kreuziger amplía la definición y resalta la relevancia para el 
presente de cualquier visión apocalíptica (7), detallando que la literatura apocalíptica posee una esencia política: "It is a statement of faith and hope in the face of a world experienced as falling apart. It is crisis literature, concerned with what is happening at the time of the writing" (7). El apocalipticismo - la doctrina, sistema o partido de lo apocalíptico - reduce los conflictos del presente a una tensión constante entre el bien y el mal y promete una liberación de las injusticias actuales. Según Lorenzo Ditommaso, "[Apocalypticism] contends that the present reality is constitutionally structured by two antagonistic and irreductible forces, which are typically identified with good and evil. It maintains that a final resolution of the conflict between these forces is both necessary and imminent, and that it is also redemptive, in the sense of a deliverance from the present reality" (474). Por ello, la presencia de imágenes y lenguaje apocalíptico en la cultura popular nos obliga a un examen de artefactos culturales y de la producción musical, literaria, plástica, grafitera y bloguera que subraya las condiciones infrahumanas de una mayoría de la población a manos de una minoría y que nos obliga a una lectura política de estos textos. Según John J. Collins, estas visiones apocalípticas ofrecen cierta esperanza a los más desesperados:

If these visions are violent, they are at least honest in bringing to expressions feelings that are almost inevitable for people who have suffered at the hands of a conquering power. Anger and fantasies of violence may be life-giving for the powerless. ... In the postmodern world we should have learned that human actions are seldom entirely pure, and that justice and brutality all too often go hand in hand. (I2)

Como declara Jacques Derrida, el tono apocalíptico siempre va más allá del momento y declara algo: "What? The truth, of course, and to signify to you that it reveals the truth to you; the tone is the revelatory of some unveiling in process" (24). En resumidas cuentas, el significado tradicional de lo apocalíptico y su aplicación exclusiva a tiempos bíblicos han sido trascendidos por las circunstancias actuales. Las visiones violentas subvierten las estructuras tradicionales de poder (especialmente el político y el económico), resaltan la guerra y sus consecuencias y ofrecen, para poder aguantar la contienda, una dosis de fe y esperanza al individuo marginado por el conflicto. Como ha escrito Parkinson Zamora, "América ha heredado la filosofía judeocristiana de la historia; aunque [las] concepciones seculares modernas no plantean un principio o un fin del tiempo (en realidad, todo lo contrario), compartimos con el apocaliptista la 
necesidad de interpretar y de atribuir una significación a nuestra experiencia de la historia" (13).

Según investigaciones de la Organización de Estados Americanos, las Naciones Unidas y la Comisión Económica para América Latina y el Caribe (CEPAL), es innegable que la pobreza, la corrupción y la violencia en México condicionan la calidad de vida y afectan el desarrollo de la

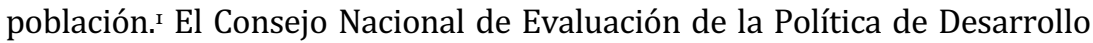
Nacional en México (CONEVAL) calcula que más de 55 millones de personas viven en situación de pobreza, un $46.2 \%$ de la población, y que un $58.5 \%$ de la población sufre carencias por falta de acceso a la seguridad social, más de 70 millones de personas (Consejo Nacional). Sobre la corrupción política, Octavio Paz denunciaba ya en 1978 el personalismo mexicano y las consecuencias para el país:

Personas de irreprochable conducta privada, espejos de moralidad en su casa y en su barrio, no tienen escrúpulos en disponer de los bienes públicos como si fuesen propios. Se trata no tanto de una inmoralidad como de la vigencia inconsciente de otra moral: en el régimen patrimonial son más bien vagas y fluctuantes las fronteras entre la esfera pública y la privada, la familia y el Estado. (99)

"La corrupción", como ha escrito Rodrigo Riquelme, "ocurre en prácticamente todos los escenarios de la vida de los mexicanos, desde los litros de $900 \mathrm{ml}$ que se despachan en muchas gasolineras, hasta la liberación de personas condenadas por un delito a cambio de una retribución económica, pasando por las cuotas que los trabajadores deben entregar a sus sindicatos". Si consideramos la definición de la violencia que ofrece la Organización Mundial de la Salud, a saber, "El uso intencional de la fuerza o el poder físico, de hecho o como amenaza, contra uno mismo, otra persona o un grupo o comunidad que cause o tenga muchas probabilidades de causar lesiones, muerte, daños psicológicos, trastornos del desarrollo o privaciones" (Krug et al. 5), no es difícil identificar una relación causal entre la violencia y la pobreza nacional. Trágicamente, estas observaciones representan un marco para comprender mejor la actualidad mexicana, particularmente para la clase media y los más necesitados del país.

Si consideramos la omnipresencia de la pobreza, corrupción y violencia en México, se comprenden la desesperación, el desengaño y la frustración a nivel nacional. Como espejo de un contexto histórico, los textos apocalípticos de raíces bíblicas retratan la barbarie del momento y, a la vez, participan en un proyecto utópico. Como ha escrito Dereck Daschke, "As much as apocalypses may hearken back to a beautiful, lost 
past (a sacred time), many may also express a yearning for a homeland where people once lived a blessed existence before being tossed into the wicked world in which they live today (a sacred space)" (464). Como rasgos generales, la literatura apocalíptica tradicional retrata el final del mundo como una catástrofe cósmica, divide el tiempo de este mundo en parcelas firmes, describe los ejércitos de ángeles y demonios que lucharán en la batalla final, detalla la nueva salvación paradisíaca que nacerá a raíz de este conflicto, utiliza la palabra gloria para separar el presente del futuro y para describir la unión final de la tierra y el paraíso (Koch 28-32). Derrida señala que el estilo apocalíptico se caracteriza por su "prediction and eschatological preaching, the fact of telling, foretelling, or preaching the ends, the extreme limit, the imminence of the last" (20), y Robert Alter y Frederick A. Kreuziger resaltan la esencia comunitaria de la literatura apocalíptica tradicional. Kreuziger, por ejemplo, indica que "Apocalyptic is a communal literature, a public and political statement about the crisis which threatens a people's identity" (I2). También expresa un rechazo, angustia e impotencia (Capote-Díaz I6) y tiende a ser una consecuencia de los tiempos que corren, ya que:

Apocalyptic literature is the product of times in which everything becomes frighteningly clear, when people realize what is at stake, when they realize it is a life and death struggle between the forces of good and evil, light and darkness, on a cosmic scale, a level which transcends the private and individual life. (Kreuziger 8)

Algunos ejemplos de literatura apocalíptica más contemporánea incluyen: The Confidence-Man (1857), de Herman Melville; The Mysterious Stranger (1916), de Mark Twain; The Day of the Locust (1939), de Nathanael West; The Invisible Man (1952), de Ralph Ellison; The Sot-Weed Factor (1960), de John Barth; Catch-22 (1961), de Joseph Heller; y $V$ (1963), de Thomas Pynchon (Alter). En la cultura popular hoy, algunos textos apocalípticos son las películas de The Matrix, la novela gráfica Promethea (1999-2005), de Alan Moore, y la novela The Stand (1978/1990), de Stephen King (Ditommaso 474-75). Según Parkinson Zamora, el uso del tropo del apocalipsis por autores americanos construye la narrativa dentro de un contexto histórico: "El empleo de estructuras e imágenes apocalípticas en la actual literatura estadounidense y latinoamericana ubica la dramatización literaria del tiempo humano entre el mito y la historia" (I4). En un contexto latinoamericano, Fernando Burgos ha estudiado las características apocalípticas en la obra de Leopoldo Lugones, Roberto Arlt, Carlos Iturra y Jaime Collyer, sin ofrecer, sin embargo, una base teórica adecuada para un análisis efectivo. 
Dentro del campo de los estudios apocalípticos, el obligado punto de referencia es el Apocalipsis de san Juan, conocido también como el libro de las Revelaciones, cuyos temas son "los acontecimientos escatológicos: la espantosa miseria que se verá bajo el dominio del Anticristo, el juicio divino contra las potencias hostiles a Dios y contra sus secuaces, el retorno de Cristo, el juicio final y las bendiciones de los elegidos de la nueva era" (Wikenhauser 2I). Redactado a finales del siglo I de la Era cristiana, el Apocalipsis comienza con una serie de cartas a las siete iglesias en las que el autor "da pruebas del poder profético de que se siente investido" (Wikenhauser 23). En la carta final a la Iglesia de Laodicea, san Juan se dirige a aquellos que poseen riquezas materiales y los critica sin tapujos, estableciendo uno de los subtemas más importantes del apocalipsis, es decir, censurar el materialismo que nos aleja de la construcción del reino de Dios en la tierra: "Porque dices: Soy rico; me he enriquecido y no tengo necesidad de nada; y no sabes que eres desdichado, miserable, pobre, ciego y desnudo" (Apocalipsis 3.17). Para elaborar esta crítica, san Juan emplea una serie de imágenes y metáforas de fenómenos naturales y animales existentes y mitológicos que serán víctimas del apocalipsis o lo anunciarán. En la visión inicial, por ejemplo, san Juan también describe a cuatro criaturas rodeando el trono: "el primero es semejante a un león; el segundo semejante a un toro; el tercero tiene rostro como de hombre; y el cuarto es semejante a un águila en vuelo" (Apocalipsis 4.7). En el Apocalipsis igual se perciben múltiples referencias a animales: leones (4.7), águilas (4.7), el cordero (5.6), "seres creados que viven en el mar" (8.9), langostas (9.3), caballos (9.17), serpientes (9.19) y un dragón (12.3). La culminación de estas criaturas es el Anticristo, "una bestia que tenía diez cuernos y siete cabezas, y sobre sus cuernos, diez diademas, y sobre sus cabezas, nombres blasfemos. La bestia que vi era semejante a una pantera, y sus patas eran como de oso, y su boca como boca de león" (Apocalipsis I3.I-2). En la visión inicial, por ejemplo, describe a Dios sentado en un trono, "Y del trono salen relámpagos y voces y truenos. Y siete antorchas de fuego están ardiendo delante del trono, que son los siete espíritus de Dios. Delante del trono un mar transparente, semejante a cristal" (Apocalipsis 4.5-6). Los relámpagos, los truenos, el fuego y el mar representan el poder $y$, en este caso, la ira de Dios ante la ineptitud humana. A lo largo del Apocalipsis se repiten ejemplos de fenómenos naturales: voces "de trueno" (6.I), "un gran terremoto" (6.I2), "el sol negro" (6.12), la luna "se volvió de sangre" (6.I2), "relámpagos" (8.5), "granizada" (8.7), "fuego mezclado con sangre" (8.7), una montaña "ardiendo en llamas" (8.8) y "un mar transparente, mezclado de fuego" (15.2). La presencia de animales y fenómenos naturales a lo largo del Apocalipsis sirve, sobre 
todo, para ilustrar la visión profética del autor, particularmente la crítica explícita e implícita del irresponsable comportamiento humano y el anuncio de los peligros que le esperan al mundo al separarse de las pautas establecidas por Dios.

Aunque no revela necesariamente el final de la existencia humana, la literatura de los siglos XX y XXI latinoamericana no carece de visiones proféticas. Obras como Cien años de soledad, de Gabriel García Márquez, Terra nostra, de Carlos Fuentes, y los cuentos "El perseguidor" y "Las babas del diablo", de Julio Cortázar (Parkinson Zamora), entre muchas otras, anuncian las futuras consecuencias de la violencia, la marginación, la corrupción y la pobreza. Como ha señalado Parkinson Zamora, "Los novelistas que emplean elementos apocalípticos, tal como los apocalípticos bíblicos, a menudo critican las actuales prácticas políticas, sociales y espirituales y proponen los medios de oponérseles y de superarlas" (I4). El apocalipsis que aparece en la literatura mexicana actual se percibe en los Poemas civiles de Trujillo Muñoz, que ilustran la decadencia social y política del país, denuncian la situación nacional y avisan de los peligros que se avecinan al apartarse, como nación, de un camino de bienestar que incluya a todos los mexicanos. Para ello, los poemas también incorporan una serie de imágenes y metáforas de animales y fenómenos naturales para denunciar la pobreza, la violencia y la corrupción que existen hoy en México. No sorprende que los versos surjan de la frontera entre México y los EE.UU., región que retrata la distancia entre los dos países y, a la vez, representa un tercer territorio que, como describió Carlos Fuentes en su novela La frontera de cristal, integra y recombina elementos de las dos potencias: el poderío mercantil, político y militar de los Estados Unidos y el peso económico de México, poseedor, después de Brasil, del segundo producto interno bruto más alto de América Latina. Poemas civiles, por ejemplo, parte de la frontera y describe una serie de animales y fenómenos naturales que sirven para ahondar en las dolencias nacionales. La mayoría de los animales que aparecen en los Poemas civiles se caracterizan por ser principalmente animales que emplean la violencia y depredan, cazando "a otros de distinta especie para su subsistencia" ("depredar"). El lobo, por ejemplo, aparece varias veces en los Poemas civiles y sirve como vehículo de una fuerte crítica social. Como ha señalado Juan Eduardo Cirlot, en las culturas romana y egipcia al lobo se le representaba como guardián valiente, y está íntimamente ligado al final de la tierra, símbolo de la aniquilación del mundo y del nacimiento del mal que, al final, saldrá de su guarida y devorará al mundo (375). En sus poemas, Trujillo Muñoz lo utiliza para ilustrar la decadencia y la corrupción política. El poema breve "Zoología mexicana", por ejemplo, comienza con la imagen de los "Lobos / 
En su banquete" (Trujillo Muñoz, Poemas 20). Otro poema, "La escena del crimen", describe a cientos de mujeres adolescentes que empezaron a desaparecer en México a finales del siglo XX y cuyos cadáveres frecuentemente se encontraban en el desierto. El poema describe cómo las mujeres salieron de sus casas vestidas y arregladas para el día, sin sospechar que la muerte las esperaba. "Todas ellas", escribe Trujillo Muñoz, "creyeron estar a salvo" (Poemas 36 ). El poema concluye:

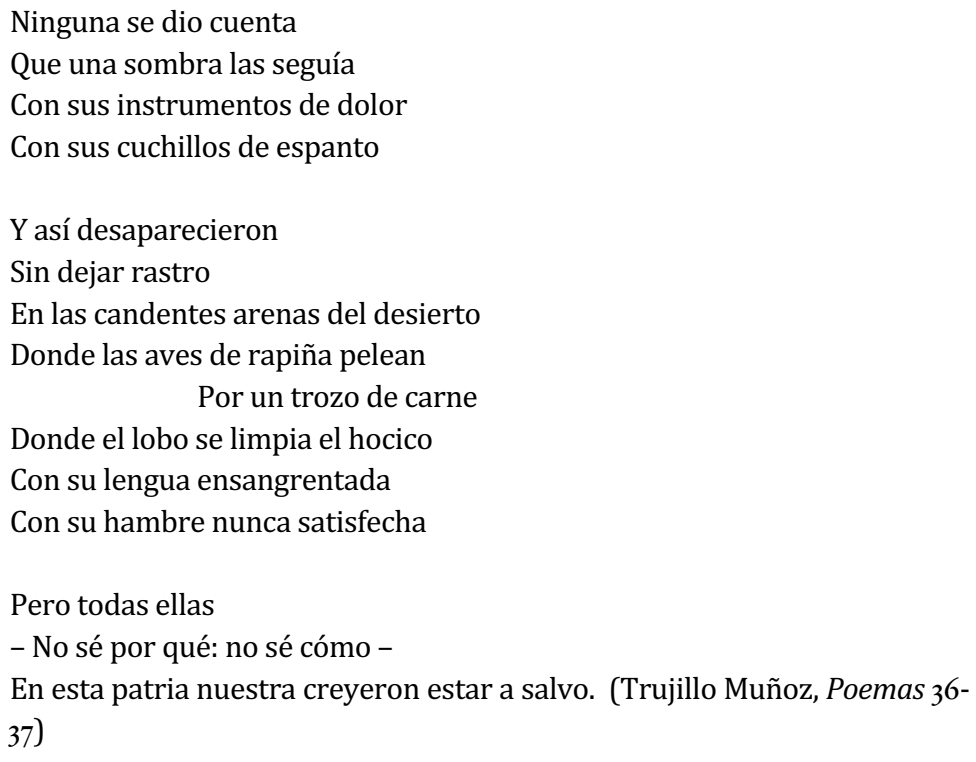

El trágico fin de las mujeres se relaciona directa e irónicamente con la sensación errónea de que las mujeres "creyeron estar a salvo" en México (Trujillo Muñoz, Poemas 37). El lobo vive en el desierto y se alimenta de lo que haya, hasta de los cadáveres de las jóvenes. Símbolo del mal, el lobo en el poema no dejará de acechar a las mujeres y anuncia un país donde nadie está a salvo. El poema breve "Escuchado en la calle" recomienda "No te demores / La noche está fea / Y andan sueltos los lobos" (Trujillo Muñoz, Poemas 56). En los ejemplos citados, dos mencionan explícitamente la alimentación como motivo del comportamiento de los lobos: su "banquete" y "hambre nunca satisfecha" (Trujillo Muñoz, Poemas 20, 30-37). El tercer ejemplo sugiere que los lobos "andan sueltos" no necesariamente por crueldad innata, sino por el instinto de sobrevivir y comer (Trujillo Muñoz, Poemas 56). Llevadas las metáforas al mundo contemporáneo, sin embargo, el contexto de los poemas resalta que los lobos - los 
depredadores de la sociedad moderna - comen hasta la saciedad: están en su "banquete", "sueltos", "con su lengua ensangrentada" (Trujillo Muñoz, Poemas 20, 30-37). Como símbolo de los asesinos y sanguinarios que empezarán a precipitar el final del mundo, el lobo es de los primeros depredadores que anticipa y allana el terreno para el apocalipsis final. La crueldad no es la antítesis de la esencia humana sino simplemente una manifestación - una sombra creciente - de ese anti-paraíso que se vislumbra en el horizonte. Y esta humanidad bestial es eminentemente humana. Como ha señalado Edgar Morin en su estudio sobre lo apocalíptico y sobre el papel protagónico que tendrá nuestra esencia humana al final de los tiempos, "The more human we become, the more brittle, complex, and bestial we are" (95).

Los versos de Poemas civiles contienen también varias referencias a aves de rapiña. "Zoología mexicana", por ejemplo, describe a los "Buitres / En las alturas / Esperando su turno" (Trujillo Muñoz, Poemas 20); el poema "La escena del crimen" sobre las mujeres desaparecidas nombra "las aves de rapiña" (Trujillo Muñoz, Poemas 36); y el poema "Himno triunfal", que ofrece una crítica del poder y de la corrupción que lo acompaña, se refiere a las "Aves de presa con sus picos ensangrentados / Bestias insaciables cuyo hedor impregna nuestros días" (Trujillo Muñoz, Poemas 58). Como símbolo del final de los tiempos, el ave de rapiña representa la relación entre la naturaleza y la muerte (Cirlot 362) y hace hincapié en esas criaturas que viven de la putrefacción. En el México de Trujillo Muñoz, las "aves de rapiña" que "pelean / por un trozo de carne" y los buitres que "[esperan] su turno" se aprovechan del trabajo de otros y atacan en el momento de más debilidad (Trujillo Muñoz, Poemas 36-37, 20). Ese "trozo de carne" ganado por los "picos ensangrentados" bien puede ser una recompensa ligera dentro de sus necesidades, pero les permite a "las aves de rapiña" mantenerse y acoplarse a su entorno, donde la misma tierra las acepta y las facilita la labor (Trujillo Muñoz, Poemas 36-37, 58). La peste que "impregna nuestros días" es la referencia más explícita al contexto histórico actual y busca construir una relación entre la violencia y agresividad de las aves de rapiña y nuestro tiempo, sugiriendo la posible proximidad de un momento culminante cuando el mal se haya apoderado de "nuestros días" y no queden más víctimas (Trujillo Muñoz, Poemas 58). Lo importante, en Trujillo Muñoz, es desenmascarar a los lobos y las aves de rapiña para mejor identificarlos. Como ha escrito David Robson, el discurso apocalíptico sirve para revelar al Otro (63). Esta revelación, sin embargo, también resalta la persistente crueldad y la agresividad que emplean las aves de rapiña para alimentarse de los despojos. Como metáfora de la corrupción endémica que sufre México, no es enredado 
establecer una relación entre las aves de rapiña - políticos ambiciosos, policías corruptos, financieros avariciosos - y el sufrimiento de la sociedad mexicana.

En Poemas civiles, las referencias zoomórficas incluyen también leones, tigres, hienas y otras bestias que simbolizan los males nacionales y reflejan la súbita llegada apocalíptica del final de los tiempos. El poema "Cacería", por ejemplo, señala que

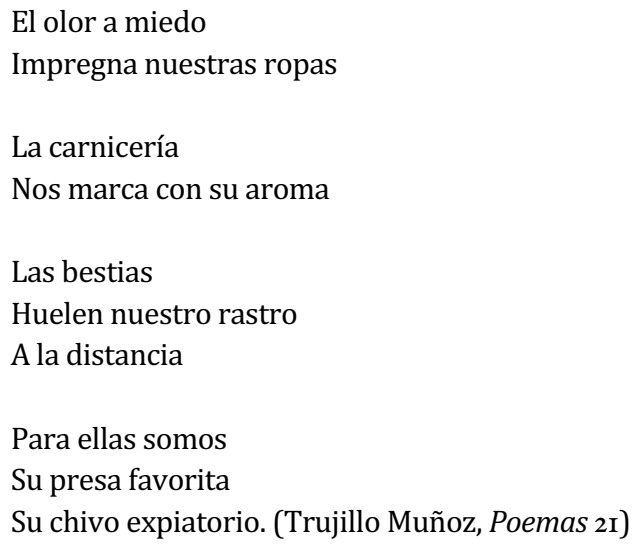

Y los versos de "Casa en vela" resaltan la importancia de proteger el hogar frente a los tiempos que corren y al final que se avecina:

La casa se ha vuelto una guarida
Un refugio contra el tiempo en su borrasca

Mientras los leones

Esperan pacientes

A que alguien dé un paso en falso

Mientras los tigres andan fuera

Muy campantes / Rugiendo. (Trujillo Muñoz, Poemas I4)

"Cacería" comienza con la asociación del narrador con su público - ese "Nuestras ropas" - para reconocer la pesadilla nacional: el pavor, marcado por la persistencia de la violencia y la corrupción. "La carnicería / Nos marca con su aroma" (Trujillo Muñoz, Poemas 2I) resalta precisamente la forma en que gran parte de la población es una sencilla presa para intereses económicos y políticos y cómo, tarde o temprano, seremos 
víctimas de cualquier serie de injusticias. Esas "bestias" que "huelen nuestro rastro / A la distancia" (Trujillo Muñoz, Poemas 2I) llevan preparando tiempo para el asalto final y para ellas representamos el bocatto di cardenale: un manjar que representa la cumbre de la exquisitez. Somos, como escribe Trujillo Muñoz, "Su presa favorita / Su chivo expiatorio" (Poemas 2I). Aparte de la marginación que se sufre y se sufrirá, las bestias buscan en "nosotros" poder construir la narrativa de la culpabilidad. Es decir, los responsables de la violencia, corrupción y pobreza no son ellas sino nosotros y nuestras equivocadas decisiones frente a la cruda realidad nacional: aceptar las circunstancias como las consecuencias de vivir en el siglo XXI, no denunciar sistemáticamente los abusos de poder, no buscar reformar ni participar en un proceso democrático que se ha visto corrompido por las influencias nocivas. Curiosamente, "Casa en vela" comienza declarando que el hogar puede ofrecer un amparo, "una guarida", "un refugio" contra las bestias que andan merodeando, esperando y "rugiendo" (Trujillo Muñoz, Poemas I4). Este mensaje, sin embargo, se va transformando paulatinamente al reconocerse que las consecuencias dañinas son evidentes y la influencia del mal llegará a entrar hasta en las propias casas. Como escribe Trujillo Muñoz, "La casa se ha vuelto un presidio / Calabozo donde la sospecha crece / Como un hongo en las sombras" (Poemas I4). Las bestias aún no habrán irrumpido literalmente en la casa, pero su influencia es palpable. "Recinto clausurado," continúa, "Donde el pánico es / Un corazón mordido por la angustia" (Trujillo Muñoz, Poemas I4). La tranquilidad y seguridad que la casa representa al principio del poema son prácticamente irreconocibles por las amenazas y provocaciones de las bestias, por la tentación de pasarse al "lado oscuro" debido a las circunstancias personales. Esa trampa y el miedo a dar el paso - o no - siembran "el pánico" y "la angustia" frente a las bestias que "esperan pacientes" a que se cometa un error por necesidad o imprudencia ${ }^{2}$ (Trujillo Muñoz, Poemas I4). Tal inestabilidad, declara Trujillo Muñoz, se debe en parte a la apatía y el hambre nacional de lucro, beneficio y profits al estilo del capitalismo estadounidense, sean a nivel individual o empresarial. Los leones y los tigres de "Casa en vela" conocen bien las debilidades de los residentes y, por ellos, "Esperan pacientes / A que alguien dé un paso en falso" (Trujillo Muñoz, Poemas I4).

Como se apreciará, la verdadera bestia, la que impulsa ese fin de los tiempos, es el ser humano. El poema "El alma nacional" emplea una serie de metáforas que critican la pasividad nacional y la tendencia tribal a vivir de la violencia: 
En este país nada cambia:

La sed de sangre es la misma

El gusto por la carroña es el mismo

Nuestros héroes son

La derrota en persona

Nuestros villanos

Supieron sacar ventaja

De sus propias traiciones

Devorarnos entre nosotros

Es nuestra más digna conducta

Nuestra mejor tradición. (Trujillo Muñoz, Poemas 3I)

El contexto del poema es transparente: "este país", México, y "la sed de sangre" y "el gusto por la carroña" (Trujillo Muñoz, Poemas 3i) que no cambian y que nos remontan a una violencia habitual, orgánica. No quedan en México ni "héroes" ni "villanos", ya que éstos se encontraron con las circunstancias propicias para profundizar en la grieta que iban abriendo y aquellos no supieron destacarse. Al final, la ironía se hace palpable: el comportamiento "digno" sería bochornoso en otro lugar y "nuestra mejor tradición" (Trujillo Muñoz, Poemas 3I) es la siniestra rutina violenta que se ha heredado de los antepasados y que se transmite a futuras generaciones mexicanas. Las múltiples tradiciones nacionales han sido apartadas por la única que, en nuestro día, realmente deja su huella en la sociedad: la violencia. México, declara el poema, sufre y vive de la muerte: se está canibalizando y no hay lugar para una reconstrucción nacional. El apocalipsis ha llegado.

Para recalcar el tono de los poemas y complementar la presencia de lobos, tigres, aves de rapiña y bestias en general, el volumen de Poemas civiles de Trujillo Muñoz igual ofrece imágenes apocalípticas de fenómenos naturales. Si bien es cierto que "En el Antiguo Testamento la tempestad acompañada de relámpagos y truenos es un símbolo corriente de la potencia y majestad de Dios cuando se revela" (Wikenhauser 89), los fenómenos naturales que aparecen en los Poemas civiles representan el otro filo de la espada: la ausencia de (un) Dios frente a la realidad mexicana. Una de las manifestaciones más evidentes a lo largo del poemario es el viento, aire activo y violento, elemento primordial por su vínculo con la respiración (Cirlot 373). En varios de los poemas, el autor ubica el viento dentro de un contexto nacional que trasciende egoísmos o 
individualidades. El poema "Supervivientes", por ejemplo, repite la pregunta "¿Qué somos ahora?" y ofrece varias respuestas: "Los hijos extraviados / De un país a la deriva", "La patria en sus rencores / La nación en sus peligros" y "Una ruina inmensa / Una mancha de sangre" (Trujillo Muñoz, Poemas Io), todas imágenes que resaltan un fin de los tiempos que corren. En la segunda estrofa se responde a la pregunta e indica que "somos" "El soplo de la historia / En la vorágine del tiempo" (Trujillo Muñoz, Poemas Io). La relación entre representaciones del viento como "el soplo" y "la vorágine" y "un país a la deriva", "La nación en sus peligros" y la "ruina" y "sangre" no es aleatoria. El final apocalíptico será testigo de la conmutación máxima de una sociedad cuyos "hijos" están perdidos, víctimas de los vientos que soplan. El título subraya lo que los mexicanos son, no lo que serán: "Supervivientes" en una sociedad construida cada vez más para y por la violencia.

El poema "Paisaje con desastre al centro" emplea un vocablo más común en las artes plásticas - "paisaje" - para resaltar la calidad objetiva de una representación poética cuya mirada recae en la calidad catastrófica de la escena. Las primeras dos estrofas, "Sobre las montañas / Una nube negra // Un viento repentino / El polvo levanta" (Trujillo Muñoz, Poemas 69) inmediatamente introducen el elemento del viento y crean un ambiente de tensión e intranquilidad. La "nube negra" que surge por encima de "las montañas" trae consigo "un viento" y "un polvo", anuncios de ese "desastre al centro" del título. Continúa el poema:

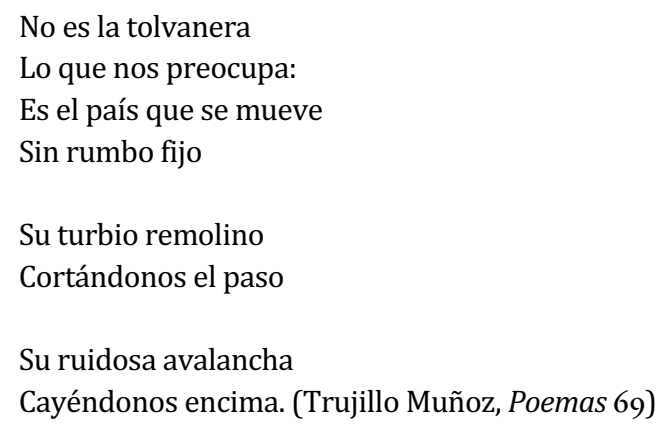

El viento no es el desastre, lo anuncia: México está perdido, y las consecuencias de este naufragio conllevan una pérdida de bienestar y la aparatosa llegada de otros tiempos, "ruidosa avalancha" (Trujillo Muñoz, Poemas 69) que enterrará al país. Curiosamente, aunque no se indagan las posibles causas del "desastre" que nombra el título, sí se lo sitúa en el "centro" del paisaje que nos ha dibujado. Es decir, el viento conlleva y 
retrata lo que, en estos momentos, está ocasionando el sufrimiento de los mexicanos.

Otros poemas emplean el viento para ofrecer una visión más alegórica del impacto de la violencia, la pobreza y la corrupción en la vida nacional. En "Tiempos difíciles" escribe Trujillo Muñoz:

\author{
Los días duros \\ Los tiempos difíciles \\ Ya están aquí. \\ Ya viven \\ Tempestad de tempestades \\ Entre nosotros. (Poemas I8)
}

Los adjetivos "duros" y "difíciles" encajan plenamente con esa "tempestad de tempestades", resaltándose de nuevo la presencia de cierta unidad - el "nosotros" - frente a lo que se le viene encima al país (Trujillo Muñoz, Poemas I8). El poema "Osamentas" describe a las víctimas asesinadas cuyos restos aparecen en lugares rurales: "Viento desatado / A la orilla del vacío / Ráfagas de tiempo / En su sombra tardía" (Trujillo Muñoz, Poemas 39), describiendo estas tragedias como señales de algo más extenso, llegado del más allá y presagio de la gran desventura final que no queda lejos: la descomposición social de la comunidad nacional. Y los versos de "Apariciones" retratan a los fantasmas que siguen presentes y continúan sufriendo igual en la muerte como lo hicieron en vida:

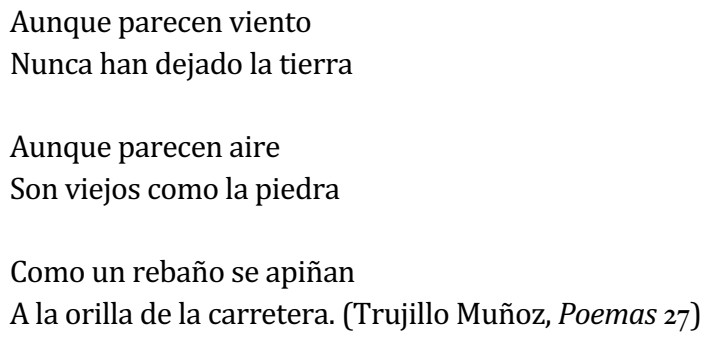

Estos espíritus siguen ligados a la vida terrenal por haber dejado algo inacabado, y se juntan "a la orilla de la carretera" para comprobar que alguien aún los recuerda, que alguien está en vías de buscar y juzgar a los culpables de su asesinato.

En el Apocalipsis de san Juan surgen igualmente referencias al viento: cuando el Cordero, por ejemplo, abre el sexto sello "y los astros del cielo 
cayeron sobre la tierra, como una higuera, sacudida por fuerte viento, deja caer las brevas" (6.I3), y la presencia de los cuatro ángeles "que retenían los cuatro vientos de la tierra para que no soplara viento alguno sobre la tierra, ni sobre el mar, ni sobre ningún árbol" (7.I0). Éstos sirven principalmente para ilustrar momentos apocalípticos y complementan momentos anteriores, esos "astros" caídos y la presencia de los cuatro ángeles. En el caso de Trujillo Muñoz, las referencias al viento igual sirven para relatar tragedias reales que ya han ocurrido. Éstas, sin embargo, emergen como aviso premonitorio de las consecuencias que están por llegar. Para Trujillo Muñoz, en Poemas civiles, la "tempestad de tempestades" (18), "el viento desatado" (39), el "viento" (27) y el "aire" (27) simbolizan la coyuntura que se vive en México y se relacionan particularmente con las consecuencias psicológicas y emotivas para la sociedad. Los fantasmas que "se apiñan / A la orilla de la carretera" (27) esperan un imposible desenlace: la resolución de sus muertes, la justificación de su sufrimiento. Éste es el verdadero viento: el que, como justa protesta, llegará para barrerlo todo y renovar la tierra nacional. Trujillo Muñoz recupera el símbolo del viento para hacerlo renovador y, a la vez, anunciador del apocalipsis mexicano que está por llegar.

Poemas civiles encajan con el tono del Apocalipsis de san Juan y resaltan cómo los fenómenos naturales son representación y presagio de la actualidad. Los terremotos, por ejemplo, aparecen en los poemas como alegoría de la vida cotidiana en México. El poema "México, 1935" destaca que "Somos una raza / Nacida en el temblor del suelo" (Trujillo Muñoz, Poemas Ior). "Trepidación" señala que "El suelo tiembla / Sin descanso // Inútil quejarnos: / Aunque caiga el cielo / Esta es nuestra casa" (Trujillo Muñoz, Poemas 97). Y los versos de "Réplicas" resaltan la explícita relación entre los movimientos sísmicos - literales o metafóricos - y el porvenir que espera: "La tierra a nuestros pies ahora suena / Como la trompeta del apocalipsis: / Música de fuego vivo: de piedra suelta / Que hace trizas con su estruendo nuestra confianza" (Trujillo Muñoz, Poemas IO3). El "temblor del suelo" que sirvió de punto de partida para la nación mexicana representa esa continua agitación de una sociedad que, desde los tiempos de la colonia española hasta la actualidad, pocas veces ha vivido tranquila, sacudida invariablemente por la violencia y la corrupción. Como señala el poema "Trepidación", sin embargo, este temblor "es nuestra casa" (Trujillo Muñoz, Poemas 97). ¿Pesimismo o realismo? Trujillo Muñoz parece destacar los dos: la realidad inspira a ser pesimistas. Compuesto en I854, la letra del himno nacional mexicano ofrece también otros temblores. La

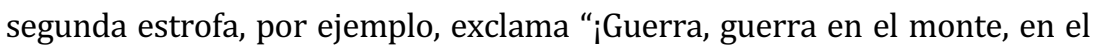
valle / los cañones horrísonos truenen," la tercera estrofa señala "Y tus 
templos, palacios y torres / se derrumben con hórrido estruendo" y una parte del estribillo que se repite a lo largo de la canción es "y retiemble en sus centros la tierra / al sonoro rugir del cañón" (González Bocanegra). Aunque es evidente que los temblores del himno nacen de armas y batallas y no de movimientos sísmicos, sí podemos observar cómo un temblor - sea cual fuere su origen - forma parte de la identidad mexicana y, en parte, de esa conciencia apocalíptica que forma parte de la mitología nacional. La creación de la patria está intrínsecamente ligada a la transformación del suelo nacional: "tronar", "derrumbes", "estruendo" y el que "retiemble en su centro la tierra" son necesarios para romper con el pasado y nacer de nuevo, ceremonia de purificación. Como ha indicado Parkinson Zamora, "Los modos apocalípticos de pensamiento y de expresión se intensifican durante los tiempos de perturbación social y de incertidumbre temporal" (227). La letra del himno nacional y la publicación de Poemas civiles más de I50 años más tarde comparten momentos de transformación y desequilibrio nacional: el primero por encontrarse en la antesala de la Guerra de Reforma (1857-1860) en México3 y el segundo por la omnipresencia de la corrupción, la violencia y la pobreza. El movimiento literal y metafórico de la tierra en los Poemas civiles - esos terremotos, esos temblores - destruye cualquier esperanza que se pueda tener que la situación general en México mejorará, distanciándose particularmente del optimismo presente en el himno nacional.

Otros poemas emplean fenómenos naturales como la lluvia, el fuego y las estrellas fugaces y confirman este diagnóstico pesimista. El poema “Diluvio," por ejemplo, describe de nuevo lo que está por venir:

\author{
Las nubes cierran toda salida \\ El cielo se ha vuelto impenetrable \\ Por todas partes \\ Los relámpagos estallan \\ La lluvia es una profecía cumpliéndose \\ Un prólogo a la calamidad \\ Que nos aguarda. (Trujillo Muñoz, Poemas 79)
}

En "Visión", Trujillo Muñoz escribe: "Sobre los escombros de mi patria / Veo pasar una estrella fugaz / Un astro refulgente" (Poemas 80). E "Idealismo alemán (versión mexicana)" declara que "El mundo arde / Porque nosotros / Su fuego alimentamos" (Trujillo Muñoz, Poemas 86). Presente en estos poemas vuelve a estar la voz del nosotros, esa primera 
persona plural que implícitamente levanta una comunidad y no se queda en simples reflexiones solipsistas ni en un ensimismamiento estéril. Su denuncia y su uso de imágenes apocalípticas y fenómenos naturales es una voz preocupada por el futuro de todos: los relámpagos y la lluvia profética anuncian "la calamidad / Que nos aguarda;" nosotros "alimentamos" la quema del mundo; "Impoluta y diamantina" reconoce que "Nunca fuimos esa patria / Impoluta y diamantina" (Trujillo Muñoz, Poemas 15); "La balada de los tiempos viles" confiesa "También nosotros / Queríamos un paraíso justo / También nosotros / Deseábamos una patria libre" (Trujillo Muñoz, Poemas 17); "Tertulia" señala que "Nos quejamos / Del país en que vivimos / De los males que nos asedian" (Trujillo Muñoz, Poemas 28); y al final del primer poema del volumen, "Lubianka revisitada", pregunta el poeta: “ ¿Podremos entre todos contar lo que aquí sucede? / ¿Tendremos el valor de no olvidar esta guerra: esta debacle: este desgarro?" (Trujillo Muñoz, Poemas 9). La voz del nosotros circula por los versos de Poemas civiles como un río que logra unir las distintas corrientes que fluyen a lo largo del poemario. Implícitamente, ese nosotros también supone un antes y un después del apocalipsis: estamos y somos aquí en el presente, estaremos y seremos México cuando pase todo. De ese nosotros dependerá cómo salir del mal trago del momento.

La obras que surgen hoy de autores afincados en el norte del país en los estados de Baja California, Sonora, Coahuila, Chihuahua, Nuevo León y Tamaulipas encajan plenamente con la actualidad mexicana, particularmente con los males que acechan al país, y ofrecen una crítica de las causas y consecuencias de tales males. Algunas de las obras narrativas de Gabriel Trujillo Muñoz, como los cuentos "Tutto mortadella," "El vecino de al lado", "La bala mágica" y "La falta de patrullas" de la colección Lucky Strike (2016), por ejemplo, exploran las repercusiones de la corrupción y la violencia en una sociedad cuyos residentes ya están acostumbrados a vivir desamparados y al margen de la ley. Dentro de la tradición literaria nacional, Poemas civiles de Trujillo Muñoz emplea una serie de imágenes innovadoras para denunciar el impacto de la corrupción y la pobreza, resaltar el sufrimiento del pueblo y anunciar la incipiente transformación apocalíptica de la sociedad mexicana. Como ha escrito el mismo Trujillo Muñoz sobre estos poemas, "Son apuntes al vuelo de un país metido hasta el fondo de una violencia que se expande, que se multiplica por todos los resquicios del cuerpo social. Son dibujos al natural del horror cotidiano, del sentimiento compartido por los mexicanos en su travesía sangrienta" ("Gabriel Trujillo"). Si recordamos los orígenes del término "apocalipsis" y utilizamos el texto de san Juan como punto etimológico de referencia, se pueden apreciar los paralelos temáticos y léxicos entre los presagios del 
Libro de Revelaciones y los versos de Poemas civiles. Individualmente, los poemas usan animales como el lobo y aves de rapiña y fenómenos naturales como el viento y el terremoto para ofrecer un fiel retrato de la situación en la que se encuentra hoy México. En su totalidad, sin embargo, los versos entran en diálogo con su época y denuncian la pobreza, la violencia, y los abusos de poder de las autoridades. Para Trujillo Muñoz, cualquier camino de posibles soluciones pasa primero por este reconocimiento: que el país está roto, que los lobos están al acecho y los terremotos irán repitiéndose. Los versos de Poemas civiles no sólo ofrecen una denuncia de la violencia y la corrupción nacional sino que implican una posible solución: la limpieza a fondo de la sociedad mexicana. En un contexto sociopolítico, el tema se proyecta fácilmente a otros países latinoamericanos donde la tasa de violencia es de las más altas del mundo (Honduras), donde las acciones del presidente y de los representantes del pueblo subvierten los principios básicos de la democracia (Nicaragua) y donde la globalización y las inversiones desenfrenadas del capitalismo internacional dan rienda suelta a la corrupción más extrema (Argentina). Para México, la expresión "perder el norte" implica toda una serie de posibles trágicas consecuencias que sirven para dar más peso aún a las observaciones críticas del autor, sirviendo como punto de inflexión para los que nos sentimos íntimamente conectados al presente, pasado y futuro del pueblo mexicano.

Xavier University

NOTAS

I Según la Comisión Económica para América Latina y el Caribe (CEPAL), la tasa de pobreza de 41.2\% de México supera a varios países industrializados latinoamericanos ("México"); y la tasa de mujeres que dedican una proporción importante de su tiempo a quehaceres domésticos y trabajos no remunerados, el 32.2\%, es la mayor de América Latina y el Caribe ("Panorama social” 27). Más de 63 millones de personas - un 53.2\% de la población - subsiste con un ingreso inferior a la línea de bienestar nacional (Consejo Nacional).

Regionalmente, los mayores índices de porcentaje de la población en pobreza se encuentran en Puebla (64.5\%), Guerrero (65.2\%), Oaxaca (66.8\%) y Chiapas (76.2\%). Desde una perspectiva social, los índices de pobreza se ven directamente relacionados con los niveles de corrupción nacional y regional. Según el Índice de Percepción de la Corrupción de Transparencia Internacional, "México obtuvo una calificación de 35 de Ioo puntos posibles" y 
a escala global pasó "del lugar 72 al 95 en siete años" (Riquelme), sufriendo las consecuencias de una extendida corrupción a nivel público y privado. En el marco nacional, por ejemplo, "que los delitos económicos en las empresas continúan creciendo, al tiempo que los controles corporativos se mantienen estancados" (Casar). El 67\% de los mexicanos cree que las leyes responden a los intereses de los legisladores o los partidos, y el 90\% piensa que las autoridades no cumplen con la ley (Casar). María Amparo Casar ha escrito sobre el "círculo vicioso de la ilegalidad" en México: cuando se comete un delito, hay un I0.75\% de "probabilidad que se denuncie", un $7.22 \%$ de "probabilidad que [se] inicie [una] averiguación previa", menos de un $3 \%$ que "la averiguación previa se resuelva" y, finalmente, un $97 \%$ de probabilidad que el delito "no se resuelva”. En México, "La corrupción alcanza el nivel de norma social: de una creencia compartida de que usar el cargo público para beneficiarse a sí mismo, a los familiares o a los amigos, es un comportamiento generalizado, esperado y tolerado de una conducta individual" (Casar).

En México, la Ley Federal Contra la Delincuencia Organizada de 1996 ofrece una lista de delitos: "[T]errorismo, delitos contra la salud, falsificación o alteración de moneda, operaciones con recursos de procedencia ilícita, acopio y tráfico de armas, tráfico de indocumentados, tráfico de órganos, corrupción de personas, pornografía, turismo sexual, lenocinio, asalto, tráfico de menores o personas que no tienen capacidad para comprender el significado del hecho, robo de vehículos, trata de personas, y secuestro" (Vilalta 282-283). En el contexto de nuestra lectura, esta lista representa un punto de comienzo para identificar a las bestias que provocan el miedo en la sociedad mexicana y que presagian un México post-apocalíptico nacido de la extrema inestabilidad estructural.

3 La guerra en I847 entre Estados Unidos y México demostró la falta de unidad política ante un enemigo común. Inspirada por ideas filosóficas europeas, la Constitución de I857 supuso una reacción contra la influencia estadounidense y promulgó, entre otros temas, la libertad de culto y enseñanza y la abolición de la esclavitud y de los fueros eclesiástico y militar. Tales cambios no fueron bien recibidos por los grupos más conservadores del país. Bajo el nombre del Plan de Tacubaya, se organizó una sublevación militar apoyada por distintos mandos que resentían su propia pérdida de autoridad. Al mando de los conservadores que buscaban imponer una constitución más conservadora estaba el General Félix María Zuloaga, mientras el General Anastasio Parrodi fue nombrado Comandante del Ejército de la coalición liberal. Aunque la Guerra de Reforma no concluyó hasta la última batalla el 22 de diciembre de I859-cuando las fuerzas liberales del General Jesús González Ortega ganaron a las fuerzas conservadoras dirigidas por el General Miguel Miramón- el reconocimiento por los Estados Unidos del gobierno de Benito Juárez el 6 de 
abril de I859 efectivamente mantuvo la intromisión del vecino del Norte en asuntos domésticos mexicanos y anunció la conclusión de la Guerra de Reforma. El himno nacional de México se compuso durante este tiempo, menos de una década después de perder la mitad de su territorio nacional como consecuencia de la guerra contra los Estados Unidos (I846-1848).

\section{OBRAS CITAS}

Alter, robert. “The Apocalyptic Temper.” Commentary 4r (I966): 6r-66. A LFRE DikenhauSER y O t to Kuss. eds. El Apocalipsis de san Juan. Trans.

Florencio Galindo. Barcelona: Editorial Herder, I969.

BURGOS, FERNAND o. "Representaciones de lo apocalíptico en cuatro escritores hispanoamericanos." Altre Modernità 9 (2013): II2-I34. CA P о т - - í AZ, VIR G IN IA. "Violencia y apocalipsis en El día señalado de Manuel Mejía Vallejo." Hipertexto I6 (2012): I6-27. CAS AR, ma Rí A A M P A o. México: Anatomía de la corrupción. za ed. S. pag. Web. CI R L O T, J.E. A Dictionary of Symbols. $\mathbf{2}^{\underline{\mathrm{a}}}$ ed. Trad. Jack Sage. New York: Dorset Press, I97I.

COLLINS, JоH J . "What is Apocalyptic Literature?" The Oxford Handbook of Apocalyptic Literature. Ed. John Jay Collins. Oxford: Oxford UP, 20I4. I-I6. COMisión económica para américa latina y el Caribe (CEPAl). Panorama social de América Latina 20r6. S. pag. Web.

—. Bases de Datos y Publicaciones Estadísticas. "México: Perfil nacional sociodemográfico." S.pag. Web.

CONSEJO NACIONAL DE EVALUACIÓN DE LA POLítiCa DE DESARROLLO NACIONAL EN MÉxico (CONEVAL). Medición de la pobreza en México y en las entidades federativas 2014. S. pag. Web.

D ASCH KE, DE REC K. “Apocalypse and Trauma.”. John Jay Collins 457-472. " Depredar." Diccionario de la lengua española. Edición del Tricentenario. Actualización 2018 . www.rae.es. Real Academia Española. S. pag. Web. DerRida, JACQues. "Of an Apocalyptic Tone Recently Adopted in Philosophy." Oxford Literary Review 6.2 (1984): 3-37.

Dit o m m A so, l o Renzo. "Apocalypticism and Popular Culture." The Oxford Handbook of Apocalyptic Literature. Ed. John Jay Collins. Oxford: Oxford UP, 20I4. 473-509.

GEWECKE, FRAUKE. “De espacios, fronteras, territorios: topografías literarias de la Frontera Norte (México)." Iberoamericana I2.46 (2012): III-I27.

GIL, EVE. "Temperamento fronterizo: ¿Existe una literatura norteña?” All About Eve. I4 de noviembre, 2005. 9:23 p.m. 
GONZÁLEZ BOCANEGRA, FRANCISCO. "Himno nacional."

https://musicaenmexico.com.mx/himno-nacional-mexicano/ S. pag. Web.

K N IC Ke R B OCK ER, D ALE. "Laberinto (As Time Goes By) de Gabriel Trujillo Muñoz: Novela de la hibridez." Revista iberoamericana 78.238-239 (2012): 193-208.

косн, KLA U S. The Rediscovery of Apocalyptic. Trad. Margaret Kohl. London: SCM

Press, 1972.

KREUZIGER, FREDER IC K A. The Religion of Science Fiction. Bowling Green: Bowling Green State U Popular P, 1986.

KRUG, ETIENNE G., LINDA L. DAHLBERG, JAMES A. MERCY, ANTHONY B. ZWI Y RAFA L L OZANo. Informe mundial sobre la violencia y la salud. Washington, D.C.: Organización Panamericana de la Salud, 2003. S. pag. Web.

LEMUS, RAFAEL. "Balas de salva. Notas sobre el narco y la narrativa mexicana." Letras Libres. Septiembre 2005: S. pag. Web.

MORIN, EDGAR. "Approaches to Nothingness." Looking Back on the End of the

World. Eds. Dietmar Kamper y Christoph Wulf. New York: Semiotext(e), I989. $8 \mathrm{I}-95$.

PALAVERSICH, DiAnA. "Paisajes invisibles: navegando el noroeste con Gabriel Trujillo Muñoz." Cruce de vías. Una mirada oceánica a la cultura hispánica. Ed. Rogelia Guedea. Xalapa: Universidad Veracruzana; México, D.F.: Editorial Aldus; Dunedin, New Zealanda: University of Otago, 20IO. 26I-284.

—. "La nueva narrativa del norte: moviendo fronteras de la literatura mexicana." Symposium: A Quarterly Journal in Modern Literatures 6I.I (2007): 9.26.

PARRA, EDUARD O ANTO NI o. "Norte, narcotráfico y literatura." Letras Libres 3 I octubre 2005: S. pag. Web.

—. "Notas sobre la nueva narrativa del norte." Jornada Semanal 27 mayo 200I: S.pag. Web.

PAz, ос тA vi o. El ogro filantrópico. Historia y política I97I-1978. Barcelona: Seix Barral, I990.

RIQUELME, RODRIGO . “20 datos sobre el problema de la corrupción en México.” El economista 27 octubre 2016. S. pag. Web.

R OB S ON, D AVID. "frye, derrida, pynchon, and the apocalyptic space of postmodern Fiction." Postmodern Apocalypse: Theory and Cultural Practice at the End. Ed. Richard Dellamora. Philadelphia: U of Pennsylvania P, I995. 6I-78. RODRÍGUEZ LOZANO, MigUEL G. "De fronteras asediadas: Sobre El festín de los cuervos de Gabriel Trujillo Muñoz." El norte y su frontera en la narrativa policiaca mexicana. Ed. Juan Carlos Ramírez-Pimienta y Salvador C. Fernández. Los Angeles, Mexico City: Occidental College, Plaza y Valdés, 2005. 6I-76. TRUJILLO MUÑOZ, GABRIE L. Biografías del futuro: La ciencia ficción mexicana y sus autores. Mexicali, Baja California, México: Universidad Autónoma de Baja California, 2000. 
—. "Gabriel Trujillo. Sobre la poesía y Poemas civiles." La otra. 30 octubre 2015: S. pag. Web.

—. Lucky Strike. Mexicali, Baja California, México: Editorial Artificios, 2016.

-. Poemas civiles. Huelva-Madrid: Editorial Amarcord, 2013.

trujillo muñoz, Gabriel y darrell b. lockhart. "Gabriel Trujillo Muñoz."

Latin American Science Fiction Writers. An A-to-Z Guide. Ed. Darrell Lockhart. Westport: Greenwood P, 2004. 199-203.

vilalta, Carlos J. "Anomia institucional, espacialidad y temporalidad en las muertes asociadas a la lucha contra la delincuencia organizada en México."

Mexican Studies/Estudios mexicanos 29.I (2013): 280-319.

vil la lo в os, josé. "Up Against the Border: A Literary Response." Border Transits: Literary and Culture Across the Line. Ed. Ana María Manzanas. Amsterdam: Rodopi, 2007.35-52.

WI KENHAUSER, ALFRED. Introducción. El Apocalipsis de san Juan. Eds. Alfred Wikenhauser y Otto Kuss. Trad. Florencio Galindo. Barcelona: Editorial Herder, 1969. 13-45.

ZAM ORA, L OIS PAR RINSON. Narrar el Apocalipsis. La visión histórica en la literatura estadunidense y latinoamericana contemporánea. México, D.F.: Fondo de Cultura Económica, 1994. 